\title{
A CONSTRUÇÃO DA "NOVA" BIOLOGIA: relações de gênero nos laboratórios do Projeto Genoma da FAPESP
}

\author{
THE CONSTRUCTION OF A "NEW" BIOLOGY \\ Gender Relations in the laboratories of FAPESP Genome Project
}

Neide Mayumi Osada1

Maria Conceição da Costa²

\begin{abstract}
Resumo:
Este artigo tem como objetivo analisar a participação de mulheres na produção do conhecimento do Projeto Genoma financiado pela FAPESP (Fundação de Amparo à Pesquisa do Estado de São Paulo). Entre 1997 e 2003, a Fapesp investiu aproximadamente R\$100 milhões no desenvolvimento do Projeto Genoma FAPESP (PGF), provocando importantes mudanças na Biologia Molecular do Brasil: as instituições de fomento às ciências passaram a privilegiá-la com importantes inversões na área; a bioinformática tornou-se um dos campos mais carentes de profissionais e, por fim, os resultados do Projeto Genoma da Xylella Fastidiosa, primeiro organismo vivo seqüenciado no Brasil, foram publicados em revistas científicas internacionais, incluindo a Nature, tornando-se assim o primeiro país fora da triade EUA-Europa-Japão a desenvolver projetos genoma. Como conseqüência desse processo, as mulheres perderam espaço enquanto "porta-vozes desta nova ciência", ocupando papéis secundários no projeto.
\end{abstract}

Palavras-chave: Gênero; Mulher e Ciência ; Biologia Molecular; Projeto Genoma.

\begin{abstract}
:
This article aims to analyse the participation of women scientist in knowledge production within the Genome Project sponsored by FAPESP (The State of São Paulo Research Foundation). Between 1997 and 2003, FAPESP invested approximately R $\$ 100$ million to develop the FAPESP Genome Project (PGF), generating major changes in Molecular Biology in Brazil: institutions devoted to fostering science and technology have been investing large sum of money; bioinformatics became one of the fields with great demand for professionals, and the results of the Xylella Genome Project, first organism sequenced in Brazil, were published in several international scientific journals including Nature, and Brazil became the first country to develop genome projects outside USA. Europe and Japan. As a consequence of this process, women scientists were loosing space as "spokespersons of this new science", playing secondary roles at the project.
\end{abstract}

Keywords: Gender; Women and Science; Molecular Biology; Genome Project.

Doutoranda do programa de pós-graduação do Departamento de Política Científica e Tecnológica, do Instituto de Geociências da Unicamp, mayumi@ige.unicamp.br.

2 Professora do Instituto de Geociências e pesquisadora do Núcleo de Estudos de Gênero - Pagu, ambos da Unicamp, dacosta@ige.unicamp.br 


\section{Introdução}

Este artigo abordará as relações de gênero no Projeto Genoma da FAPESP $^{3}$ [PGF], a partir da análise dos dados obtidos sobre os projetos genoma da Xylella Fastidiosa [PGX], bactéria causadora da doença do amarelinho que ataca as laranjeiras de São Paulo, da Cana-de-açúcar [PGC] e da Xanthomonas Citri [PGXac], bactéria causadora do cancro cítrico, sob a perspectiva dos estudos de gênero e ciência. O presente artigo é parte da dissertação de Mestrado ${ }^{4}$, defendida em agosto de 2006 na Universidade Estadual de Campinas, no Departamento de Política Científica e Tecnológica.

Para a construção dessa análise, foram coletados dados quantitativos acerca da participação de mulheres na graduação, pós-graduação, docência e pesquisa no Estado de São Paulo. Além disso, foram extraídos dados da FAPESP sobre os investimentos em pesquisa e concessão de bolsas por ano e sexo. Entrevistas semi-estruturadas - 10 entrevistas no total, homens e mulheres em número igual - permitiram analisar a participação das mulheres nas ciências biológicas, ajudaram a entender a produção do conhecimento, as atividades desenvolvidas por cada pesquisador e a examinar as barreiras que levam à participação desigual de homens e de mulheres nas ciências e na coordenação de grandes projetos de pesquisa.

\section{O Projeto Genoma da FAPESP: predomínio masculino}

Os indicadores de Ciência e Tecnologia (1996) do País demonstravam a necessidade de promover a área de Biologia Molecular, cujo desdobramento resultou no desenvolvimento do Projeto Genoma da FAPESP em 1997. Inicialmente o projeto previa o envio de pesquisadores ao exterior para aprender as técnicas de seqüenciamento e a análise do material genético, o que foi considerado pela coordenação como uma maneira pouco eficiente. É preciso recordar que a FAPESP, o $\mathrm{CNPq}^{5}$ e a $\mathrm{CAPES}^{6}$ tinham programas de bolsas no exterior já consolidadas e, mesmo assim, os estudos da Biologia Molecular continuavam isolados e embrionários.

Naquele momento, o principal desafio não era a formação de recursos humanos, mas melhorar a infra-estrutura dos laboratórios de Biologia e capacitar pesquisadores na execução de projetos genoma. Como muitos pesquisadores afirmaram durante as entrevistas, os equipamentos e os insumos necessários para a montagem de um laboratório de Biologia Molecular são muito caros e, na maioria das vezes, a universidade não tem como arcar com tais custos. Somado a isso, projetos genoma não podem ser realizados por apenas um único laboratório, pois o seqüenciamento de um organismo vivo, em 1997, poderia levar muito tempo e, antes da sua conclusão, ele seria um estudo obsoleto.

Dado estes fatos, o programa genoma pautou um conjunto de metas, como conectar laboratórios de biologia espalhados pelo Estado de São Paulo, estudar um organismo vivo simples, como as bactérias, para que o processo de aprendizagem fosse relativamente rápido, equipar todos os laboratórios envolvidos, formar uma rede de pesquisa sobre o genoma e criar um laboratório 
virtual, pólo articulador e armazenador de dados e informações.

O núcleo de coordenadores e consultores que organizou o projeto genoma naquela época foi composto por aproximadamente dezoito pesquisadores- todos homens - sendo a maioria especialista em Biologia Molecular, Bioquímica e Agronomia. Fizeram parte da equipe cientistas das áreas da Medicina, da Veterinária, da Biomedicina, da Farmácia e da Ciência da Computação. Foram convidados consultores internacionais da Inglaterra, da Bélgica e da França, com experiência em projetos genoma para organizar a pesquisa no Brasil.

Para a seleção dos coordenadores de laboratório de seqüenciamento, foi aberto um edital público para pesquisadores da área da Biologia Molecular, sendo avaliado, principalmente, o currículo do pesquisador.

A análise dos curriculos dos pesquisadores que participaram do PGX apresenta diversas características em comum: a maioria dos pesquisadores fez o doutorado, parte do doutorado ou o pós-doutorado em importantes instituições internacionais (Estados Unidos, França ou Alemanha) na área da Biologia Molecular, entre o final dos anos 1980 e meados dos anos 1990; a maioria havia participado especificamente de projetos de seqüenciamento de DNA, ainda que o método aprendido tenha sido outro, e, finalmente, todos os coordenadores de laboratório tinham experiências em análise do mapeamento genético.

O PGX integrou 34 laboratórios no Estado de São Paulo, reunindo mais de 207 participantes, sendo $53 \%$ homens e $47 \%$ mulheres; $69.5 \%$ dos laboratórios foram coordenados por homens e $30.5 \%$ por mulheres; entre os pesquisadores, $52 \%$ eram mulheres e $47 \%$ homens. Participaram três universidades estaduais públicas, Universidade de São Paulo (USP), Universidade Estadual Paulista Júlio de Mesquista Filho (Unesp) e Universidade Estadual de Campinas (Unicamp), institutos de pesquisa como o Instituto Butantã, o Instituto Ludwig e a Fundação Fundecitros.

No Projeto Genoma da Cana-de-açúcar, foram 76 laboratórios que se dividiram em laboratórios de seqüenciamento, de data mining e de bioinformática, localizados nas regiões Sudeste e Nordeste do Brasil. Integraram à equipe 237 pesquisadores, entre coordenadores, pesquisadores e técnicos de laboratório, sendo 140 no Estado de São Paulo e 97 nos demais Estados.

Tabela 1: Participantes do Projeto Genoma da Fapesp por projeto, função e sexo - em porcentagem

\begin{tabular}{l|lll|lll}
\hline \multirow{2}{*}{\multicolumn{1}{c|}{ Projeto }} & \multicolumn{3}{|c|}{ Pesquisadores } & \multicolumn{3}{c}{ Coordenadores } \\
\cline { 2 - 7 } & T & F & $\%$ & T & F & $\%$ \\
\hline Genoma da Xlylella & 171 & 89 & 52,0 & 36 & 11 & 30,6 \\
\hline Genoma da Cana & 237 & 122 & 51,5 & 61 & 21 & 34,4 \\
\hline Genoma da Xanthomonas & & & & 26 & 11 & 42,3 \\
\hline Total Global & $\mathbf{4 0 8}$ & $\mathbf{2 1 1}$ & $\mathbf{5 1 , 7}$ & $\mathbf{1 2 3}$ & $\mathbf{4 3}$ & $\mathbf{3 5 , 0}$ \\
\hline
\end{tabular}

Fonte: FAPESP, 2005. Elaboração própria..

Legenda: $\mathrm{T}$ : total; $\mathrm{F}$ : feminino 
O PGC reuniu um grupo ainda maior que o PGX, em que participaram, além das três universidades públicas paulistas, o Instituto Agronômico de Campinas, o Instituto Biológico, o Instituto Butantã, a Fundação Copersucar, a Empresa Pernambucana da Pesquisa Agrícola, o Laboratório de Luz Síncroton, a Embrapa ${ }^{7}$, algumas universidades privadas do interior do Estado de São Paulo e, além disso, participaram da rede da cana-de-açúcar pesquisadores de outros Estados brasileiros, entre eles Rio de Janeiro, Alagoas, Pernambuco, Rio Grande do Norte, Bahia, Paraná e Sergipe. O envolvimento de universidades federais, fora do Estado de São Paulo, contou com recursos do governo federal e das Fundações de Amparo à Pesquisa [Faps], já que a FAPESP não financia projetos fora do Estado.

Menos grandioso, mais focalizado e menor, e tão importante quanto, o Projeto Genoma Xanthomonas Citri [PGXac] reuniu um grupo menor de pesquisadores e laboratórios. Foram apenas 13 laboratórios, 11 de seqüenciamento e 2 de bioinformática. A rede restringiu-se às três universidades estaduais paulistas, USP, Unicamp e Unesp. Foram 8 coordenadores principais, dentre os quais duas mulheres; entre os 15 coordenadores de laboratório de seqüenciamento, 9 eram mulheres.

As mulheres coordenadoras de laboratórios de seqüenciamento do PGXac representaram $60 \%{ }^{8}$ do total de coordenadores; os dados sobre os demais pesquisadores não estão disponíveis nas páginas web do projeto, no entanto, informações acerca dos demais projetos genoma permitem afirmar que a participação das mulheres pesquisadoras foi de aproximadamente $52 \%$.

O Projeto Genoma Xylella não pode ser definido simplesmente como um projeto acadêmico; ele foi, antes de tudo, a escola na qual pesquisadores aprenderam, cooperativamente, a produzir conhecimento em genômica, proteômica, expressão e análise de seqüenciamento genético. O projeto trouxe uma série de benefícios como a modernização da infra-estrutura dos laboratórios, a capacitação de grupos de pesquisa em genômica e a visibilidade internacional de seus pesquisadores. Além disso, o segundo projeto da Fapesp, - Genoma da Cana, foi importante pela disseminação do método de pesquisa em âmbito nacional:

"A FAPESP permitiu que participassem, de uma forma muito singela, outros grupos [da Biologia Molecular] do país inteiro no projeto da cana. E assim a gente poderia disseminar de maneira mais rápida para outros estados."(Entrev. 5). ${ }^{9}$

A Biologia Molecular redirecionou esforços e recursos permitindo a construção de uma nova área do conhecimento. O Projeto Genoma FAPESP chamou a atenção da mídia nacional por se tratar de uma área de ampla divulgação científica e pelos possiveis resultados esperados. As colunas de ciências dos jornais Folha de S. Paulo, O Estado de S. Paulo e outros jornais trazem constantemente um grande número de matérias sobre projetos genoma, biotecnologia, estudos sobre células-tronco entre outros. Recentemente foi anunciado o "desvendamento do código genético" do guaraná, espécie nativa da região do amazonas, por pesquisadores da região, tais informações confirmam o crescimento da área no país, ratificam a sua importância, mas 
imediatamente nos remetem à pergunta: "E agora, o que fazer diante do material seqüenciado?

\section{Diferenças de gênero na produção das ciências: obstáculos a contornar}

Na construção da carreira da mulher cientista, há questões que têm sido ignoradas por parte das instituições de ensino e fomento à pesquisa, como a maternidade e os cuidados dos filhos pequenos. Tais questões serão aqui abordadas por terem sido foco de intensa discussão durante a realização das entrevistas, tanto por parte das pesquisadoras, como também pelos coordenadores e coordenadoras de laboratórios.

A condição de bolsista não garante às pesquisadoras uma situação estável e confortável para que elas possam decidir-se pela maternidade. As bolsistas contam apenas com a compreensão dos seus orientadores. Sobre as pesquisadoras-mães incidem quatro grandes questões: a) manutenção da bolsa de pesquisa; b) entrega do trabalho no prazo e geração de bons resultados de pesquisa; c) dificuldades em complementar a pesquisa no exterior e, d) impedimentos para retornar ao laboratório.

A questão da maternidade, dos cuidados com filhos e suas conseqüências sobre a produtividade científica, foram analisado por Kywik e Teigen (1996) e indicam que mães com filhos menores de seis anos produzem $60 \%$ menos que seus pares homens, a partir do momento em que os filhos crescem e atingem idade superior a onze anos, a diferença na produtividade é $8 \%$ menor em relação à produtividade dos homens. Além disso, outros dados mostram que mães com filhos de até onze anos, dedicam-se à pesquisa 5.5 horas por semana a menos que seus colegas homens.

Outra questão, analisada por Kywik e Teigen (1996), refere-se às dificuldades que a mulher tem em integrar-se às redes informais de trabalho, em ambientes excessivamente masculinos. Participar de uma rede de pesquisa significa a ampliação de trabalhos cooperativos, posto que as atividades coletivas estimulam a produtividade e as publicações em co-autoria. Com isso, aumenta também a qualidade e que, por sua vez, aumentam as chances de aprovação em revistas científicas importantes:

"Percebemos que a falta de colaboração em pesquisas com colegas, dentro ou fora do departamento, tem impacto negativo significante sobre a produtividade de mulheres, mas não na produtividade masculina" (Kywik e Teigen, 1996, p. 69).

No entanto, no caso da pesquisa realizada com as biólogas brasileiras, a maternidade e os cuidados com os filhos têm conseqüências também na carreira futura da pesquisadora, e não somente nos índices de produtividade. De acordo com pesquisadores entrevistados, os orientadores devem notificar às agências financiadoras o afastamento da pesquisadora por problemas de natureza pessoal, para que, dependendo da situação, interrompam o pagamento das bolsas até o retorno da aluna. O não-encaminhamento de 
relatórios e prestações de contas às agências podem acarretar na perda total da bolsa:

"muitas desistem...até porque o nosso sistema não preserva isso. Se você for bolsista FAPESP e tiver um filho, a sua bolsa é cortada. Um absurdo...isso é muito difícil. É importante ter bom senso, é claro que se a pessoa for optar por fazer um doutorado, o ideal é que ela planeje filhos para depois, mas a gente sabe que nem sempre é possível, eu mesmo... minha ex-mulher teve filho durante o doutofado, minha atual mulher teve filho durante o mestrado, então, acontece...ainda mais porque é a idade reprodutiva das mulheres" (Entrev. 9) ${ }^{10}$.

No Brasil não existem dados indicando o número de pesquisadoras que desistem do mundo das ciências por causa da gravidez ou cuidados com filhos; no entanto, de acordo com artigo publicado pela Revista Nature, um survey realizado pela “Germany's Center of Excellence for Women in Science sugere que mais de $40 \%$ das mulheres optam por não terem filhos, outras desistem da academia" (Gewin, 2005, p.446), pois, em muitos casos, o nascimento de um bebê pode prejudicar as ambições das mulheres na carreira científica.

Como analisa Léon Orozco (1998) acerca da participação da mulher nas ciências:

\begin{abstract}
tais vantagens de habilidades percebidas na mulher não necessariamente implicam que serão reconhecidas pela comunidade científica, cuja elite notadamente masculina tende a privilegiar seus pares de mesmo gênero. 0 desempenho profissional da mulher pode ser afetado por esta prática na medida em que a falta de estímulo ou reconhecimento diminui seu entusiasmo pela carreira profissional e pode até levá-la, em casos extremos, a abandonar o mundo acadêmico e ocupar-se integralmente das responsabilidades familiares e da educação de seus filhos.
\end{abstract}

De acordo com os dados apresentados por Velloso (2005), a idade média dos alunos de Bioquímica no Brasil, em 1998, ao concluir o doutorado era de 34.7 anos. Isso sugere que é aproximadamente entre o doutorado e o pósdoutorado que muitas pesquisadoras planejam ter o primeiro filho. Foi justamente o que ocorreu com três pesquisadoras de um dos laboratórios visitados durante a pesquisa: tiveram filhos durante o programa de pósgraduação.

O outro fato marcante e divisor de águas na vida de uma pesquisadora que está constituindo família durante o periodo de sua formação é a necessidade de se fazer estágio em laboratórios de Biologia no exterior. Essa vivência para os pesquisadores da Biologia Molecular parece ser crucial na formação desses indivíduos ou do grupo de pesquisa. Para entender o caso, todos os pesquisadores entrevistados participaram de estágios no exterior e, por esta razão, foram selecionados para o PGF. Suas experiências permitiram conhecer técnicas de seqüenciamento de organismos vivos e entender o processo da "anotação", ou análise do material seqüenciado. Além disso, as parcerias entre laboratórios nacionais e internacionais garantem que a instituição mantenha constante a vinda e a ida de estudantes brasileiros e estrangeiros. Muitos destes laboratórios contam com recursos financeiros 
garantidos pela FAPESP, CNPq ou CAPES, facilitando a troca de conhecimento.

Mas nem sempre a possibilidade de fazer estágio no exterior acontece num momento adequado da vida de uma pesquisadora. Uma entrevistada queixava-se que as suas três alunas da pós-graduação não poderiam fazer o estágio no exterior por causa dos filhos:

"Eu tenho 3 alunas que tiveram filhos no início da pós-graduação, e elas não podem ir [ao exterior fazer o estágio]. Elas teriam bolsas, teriam oportunidade de fazer parte do doutorado nos Estados Unidos, mas elas têm filhos e elas já me disseram que não tem como ir" (Entrev. 2) ${ }^{11}$.

Para essa pesquisadora, não complementar a formação em laboratórios no exterior empobrece a pesquisa de doutorado, reduz as chances de produzir bons resultados e pesará na construção futura da carreira dessas pesquisadoras.

Para os rapazes, o nascimento de um filho altera o cotidiano de suas vidas, mas não implica em grandes conseqüências em sua carreira profissional. Ele não terá de abrir mão de um periodo no exterior por causa da criança, na maioria das vezes, o marido vai e deixa a criança com a mãe. Foi o caso do estudante, orientando de uma das entrevistadas, que foi para a Alemanha para o estágio de um ano.

Além dos problemas e dramas que cada pesquisadora enfrenta com a chegada de um filho, há ainda o retorno ao laboratório. Após o nascimento, se tudo ocorrer nas condições adequadas, a sua volta pode levar pouco mais que quatro meses, sendo outra situação desafiadora, pois, muitas vezes, o estágio da pesquisa em que ela participava é outro, novas descobertas são feitas, novas técnicas são utilizadas e, se é iniciado um novo projeto, a reintegração ao grupo de pesquisa demandará mais tempo por parte de outros pesquisadores que precisarão introduzi-la à nova temática; a pesquisadora-mãe ainda terá de aprender, rapidamente, o que foi feito durante a sua ausência.

Não só as bolsas FAPESP, como também as bolsas CAPES e CNPq, entre outras, são cortadas no caso de afastamentos prolongados e ausência de produtividade. Naturalmente, não se trata de premiar bolsistas-mães, mas é preciso pensar seriamente em mecanismos que facilitem o retorno da pesquisadora à universidade, tais como abrir as creches nas universidades e faculdades para alunas da graduação e da pós-graduação, ampliar o prazo para entrega da tese (se necessário), não cortar as bolsas durante o período de afastamento, entre outros mecanismos.

A cientista e Prêmio Nobel Christiane Nüsslein-Volhard, diretora do Instituto Max Planck, importante centro de estudos em Biologia, criou uma fundação para viabilizar o pagamento de bolsas no valor de US $\$ 490$ dólares a cinco pesquisadoras do laboratório que estavam na iminência de desistir das ciências pelo nascimento dos filhos [Nature, 2005, p. 297] ${ }^{12}$. A bolsa tem como objetivo ajudar as mães nos cuidados com o bebês e garantir seu retorno ao laboratório.

Para resolver o impasse entre a licença maternidade e o andamento da pesquisa, a entrevistada $n^{\circ}$. 10, atualmente coordenadora de um laboratório 
"[sobre a maternidade] Eu, de certa forma me preparei para que eu não ficasse quatro meses totalmente parada. Então, eu criei toda uma infra-estrutura na minha casa, acesso meu computador aqui. Eu moro muito perto daqui, então, os alunos iam toda a semana na minha casa fazer reuniões, eu não estava fisicamente aqui, eu consegui montar uma estrutura, e tudo continuou andando, nada ficou parado...talvez se me perguntasse, poderia ter andado tudo mais rápido, mas parado nada ficou. E eu acho que ninguém aqui sentiu que foi uma perda pro laboratório, e hoje em dia o que eu aprendi foi a me organizar completamente" (Entrev. 10).

No entanto, a maioria das mulheres pesquisadoras em posições juniores não desfrutam de condições necessárias para criar mecanismos que garantam seu retorno ao ambiente do laboratório. O corte de bolsas de pesquisadoras durante a maternidade e, a (quase certa) perda da contribuição futura dessa profissional é um fenômeno tão bizarro que somente pode ser compreendido como um resquício do passado dessas instituições (universidades e centros de pesquisa) que desde sua constituição até recentemente são percebidos como redutos exclusivamente masculinos. Cortar bolsas de pesquisadoras durante a maternidade só poderia ser uma invenção masculina.

No que se refere às barreiras criadas no ambiente acadêmico, a construção de líderes de pesquisa ou de área parece ter peso importante. Os dados apresentados sobre "projetos temáticos" mostram a reduzida participação feminina na construção de projetos coletivos que exigem grandes somas de recursos financeiros. A aprovação de $36 \%$ dos projetos temáticos às pesquisadoras não deve ser considerado um mero resultado da proporção de projetos encaminhados por mulheres ${ }^{13}$. Informações coletadas apontam para uma série de obstáculos que as mulheres enfrentam ao longo da carreira acadêmica, desde a relação apaziguadora entre colegas do departamento, como afirma uma das entrevistadas, até a importância que a FAPESP atribui ao líder da pesquisa.

Tabela 4: Distribuição de recursos FAPESP concedidos às ciências biológicas, por ano e sexo - 1992 a 2005

\begin{tabular}{l|l|l|l|l|l|l}
\hline \multirow{2}{*}{ Tipos de recursos } & \multicolumn{3}{|c|}{ Total de propostas recebidas } & \multicolumn{3}{|c}{ Propostas aprovadas } \\
\cline { 2 - 7 } & $\mathbf{T}$ & $\mathbf{F}$ & $\boldsymbol{\%}$ & $\mathbf{T}$ & $\mathbf{F}$ & $\% \mathbf{F}$ \\
\hline Bolsas País & 15575 & 10446 & 67.1 & 9962 & 6628 & 66.5 \\
\hline Auxílio Genoma & 345 & 129 & 37.4 & 257 & 97 & 37.7 \\
\hline Auxílio Regular & 3729 & 1913 & 51.3 & 2802 & 1454 & 51.9 \\
\hline Projetos Temáticos & 352 & 133 & 37.8 & 222 & 80 & 36.0 \\
\hline
\end{tabular}

Fonte: FAPESP, 2006/ Elaboração Própria. T: Total/ F: feminino

O problema da liderança foi colocado como um dos principais empecilhos para a ampliação da participação feminina, não bastando que o 
pesquisador atenda a todos os requisitos que a instituição exige. De acordo com um dos pesquisadores do genoma:

"A FAPESP tem uma caracteristica muito importante que é a busca das lideranças, de buscar as pessoas que são mais ativas naquelas determinadas áreas. Talvez você tenha mulheres mais ativas em outras áreas, não necessariamente na Biologia Molecular, mas em outras áreas dentro da Biologia, como na Botânica, na Microbiologia, etc. Mas você tem razão, mas qual é a sua interpretação?" (Entrev. 5) ${ }^{14}$.

Outra entrevistada atribui o problema à falta de lideranças das mulheres:

“Ai é a competição pela liderança. Isso não tem jeito, mas mesmo sem liderança eles conseguem a aprovação dos projetos. Isso é uma coisa séria, viu?...As mulheres abrem mão de serem coordenadoras de projetos. Eu também já abri mão da coordenação de um projeto, pela lógica do momento. É a importância da harmonização no ambiente de trabalho...A mulher não é tão decidida quanto o homem. Eu vejo isso...Liderança, nós não temos tanta liderança quanto os homens" (Entrev. 1) $)^{15}$.

Rossiter (1993) utiliza a expressão Efeito Matilda, para descrever o que Robert Merton chamou de Efeito Mateus, em alusão ao texto bíblico [àqueles que têm será acrescentado, àqueles que não têm, será tirado, Mateus 13:12]. Para Merton, esse efeito refere-se à situação de reconhecimento dos cientistas que estão no topo da carreira em detrimento dos pesquisadores menos conhecidos, ou dos casos da descoberta múltipla nas ciências cuja autoria é sempre, ou quase sempre, atribuida ao pesquisador mais famoso, ajuda a compreender a sub-representação feminina nas ciências.

No caso das pesquisadoras na área da Biologia, o Efeito Matilda tem conseqüências sobre a sua produtividade e sobre a sua vida acadêmica. Para garantir um ambiente harmonioso ou para garantir a obtenção de recursos, pesquisadoras optam por ceder a coordenação da pesquisa aos cientistas mais titulados. Quando ocorre a divulgação dos resultados da pesquisa na mídia, o coordenador do projeto é o indivíduo mais procurado pelos meios de comunicação, transformando-se em porta-voz do projeto e da instituição que representa, tornando invisiveis os demais pesquisadores.

O mundo das ciências poderia ser diferente?

Analisar as contribuições de pesquisadores nas ciências por gênero não é tarefa fácil, uma vez que valores como neutralidade, objetividade e racionalidade atribuidos à ciência e aos cientistas dificultam a percepção de atores múltiplos no fazer ciência.

A finalização do PGX ocorreu pelo empenho de pesquisadoras que se dedicaram ao trabalho de "finishing", fechamento da seqüência completa do genoma, demandou dedicação e paciência, como afirmou a pesquisadora Ana Claudia Rasera, (Fioravanti, 2000): "é como montar um quebra-cabeça". A conclusão do PGX por sete pesquisadoras não foi por acaso, as mulheres são maioria nos laboratórios de Biologia Molecular, e de acordo com umas das entrevistadas: 
"As mulheres têm muito mais habilidade para trabalhar com estes métodos mais novos $[\ldots]$

[sobre a participação da mulher no PGF]. Se não fosse a mulher no projeto Genoma, eu tenho certeza que os homens não teriam conseguido fazer um trabalho de "anotação" de qualidade [grifo nosso].

Toda aguela qualidade de leitura aconteceu porque tinha muita gente boa, mulheres basicamente, trabalhando no laboratório" (Entrev. 1) ${ }^{16}$.

Uma outra pesquisadora afirma:

"O que a gente percebe é que a área de Biologia celular, Biologia Molecular é um número um pouco maior de mulheres, é porque nem sempre os homens gostam de trabalhar num laboratório. É preciso uma certa aptidão e, às vezes, os homens gostam... ou de uma área mais voltada para a Computação ou engenharia, então, aqui é uma escola de engenharia. Nós temos, mais ou menos, equilibradas as disciplinas voltadas para as ciências básicas, e as disciplinas voltadas para as áreas mais aplicadas, tipo engenharia, irrigação, hidráulica, tem também a parte de zootecnia, tudo isso" ( Grifo nosso, entrev. 2) ${ }^{17}$.

As rotinas dentro do laboratório não são poucas, e o uso das metáforas utilizadas no laboratório de biologia para descrever os processos de preparação dos materiais para análise são vários, como "ritual de chá" e "receitas de bolo". Os protocolos ou "receitas de bolo" só se alteram quando um pesquisador mais experiente otimiza, muda a quantidade de "ingredientes" utilizados na preparação do "bolo" ou do material a ser seqüenciado. Os equipamentos de seqüenciamento funcionam de maneira relativamente simples; no entanto, nenhuma etapa poderia ser pulada ou realizada de qualquer maneira:

"sim, eu falo pro pessoal: é o ritual do chá [sobre o procedimento durante a preparação do equipamento de seqüenciamento]. Eu não posso falhar em nenhum detalhe. Eu brinco com o pessoal daqui. Se eu deixo isso aqui fora, não funciona. Se eu não coloco o tampão corretamente, dá errado" (Entrev. 6) ${ }^{18}$.

A metáfora da "receita de bolo", para descrever os protocolos estabelecidos no processo de preparação do material a ser seqüenciado pelo Prisma 3700 , equipamento de seqüenciamento genético adquirido pela FAPESP em 1997, sugere um ambiente mais feminino.

Nos laboratórios de bioinformática, o universo é outro. A vidraria dá lugar aos computadores, e o ambiente se torna mais masculino. Isso se explica porque uma parte da equipe que cuida das atividades mais técnicas do laboratório são pesquisadores das áreas das ciências exatas que têm noções de Biologia Molecular e pesquisadores biólogos em posições mais seniores trabalhando na "anotação"19 do projeto. A anotação é a parte que analisa o genoma seqüenciado, é o momento em que novas hipóteses são geradas a partir do material seqüenciado, e é também a parte mais criativa do processo de produção da Biologia Molecular.

Na Biologia Molecular e nos projetos genoma, o que parece ocorrer é 
uma espécie de "divisão sexual" na qual mulheres cuidam do processo de seqüenciamento e montagem do genoma; enquanto que os rapazes se dedicam à análise do material, como afirmou uma das pesquisadas:

Na parte técnica, você conheceu um agora que é o Marcelo, ele tem recursos do "jovem pesquisador"... Na bioinformática, eles são muito bons...Então vou dizer, aqui no laboratório técnico participam as mulheres, mas na bioinformática são os homens, os homens ficam na parte computacional e são muito bons. Eu já reparei isso, os homens têm muito mais habilidade com raciocínio do que na mão...Raciocínio lógico do tipo, acertar... eles gostam, preferem raciocínio lógico no computador trabalhando na seqüência, na análise da anotação, são muito melhores...E as mulheres são muito melhores no laboratório na parte do manuseio, da técnica da medida...Então pesa essa dupla, existe aqui dentro, são trabalhos paralelos ou complementando um ao outro. O primeiro entra na seqüência e outro entra na análise. Existe esta parceria (Grifo nosso, Entrev. 1) ${ }^{20}$.

De acordo com outro entrevistado ${ }^{21}$, nos laboratórios da Alellyx ${ }^{22}$, para citar um exemplo das mudanças na estrutura do laboratório de Biologia Molecular, os pesquisadores dedicam mais tempo desenvolvendo atividades de pesquisa no laboratório de bioinformática do que sobre a bancada do laboratório. O pesquisador só volta para o laboratório de Biologia no momento em que deve testar as hipóteses formuladas no computador.

O Prêmio Claudia de $2000^{23}$ laureou na categoria ciências sete cientistas mulheres que participaram do $\mathrm{PGX}^{24}$ e foi conferido ao grupo pelo trabalho meticuloso em montar os $10 \%$ restantes do seqüenciamento do genoma da Xylella, pelo desempenho dessas pesquisadoras e pelo trabalho concluido antes do tempo previsto. E, como afirmou Rasera em entrevista à Revista Pesquisa da FAPESP, o trabalho final de montagem não é banal; muitos projetos genoma no exterior foram abandonados porque a equipe não conseguiu concluir o fechamento.

O processo de produção do conhecimento da Biologia Molecular é cansativo porque os procedimentos exigem que os protocolos sejam realizados conforme as receitas, e esse fato aumenta a rotatividade de pesquisadores e o afastamento de um número maior de homens dos laboratórios. Como afirmou Walter Gilbert, pesquisador do Projeto Genoma Humano americano, tais procedimentos deveriam ser terceirizados para que os cientistas pudessem se dedicar às atividades mais analíticas.

Dessa forma, a maneira como o PGX foi apresentado por alguns dos nossos entrevistados, sugere a vigência no âmbito da ciência de uma divisão sexual do trabalho similar à que se verifica atualmente no exercício das demais atividades humanas: tarefas repetitivas e monótonas são atribuídas às mulheres, como se elas fossem "naturalmente" mais adequadas, ou mais conformadas para isso; enquanto que os trabalhos cuja exigência é o raciocínio e o pensamento abstrato, ficam a cargo dos homens.

E poderia ser diferente? Certamente não, como argumenta Velho e Prochazka (2005):

"Os novos sociólogos da ciência vêm argumentando há anos que não há nada no 
mundo científico que o diferencie das demais esferas da atividade humana. A ciência, como qualquer outra forma de conhecimento, é socialmente construída e incorpora os valores e práticas de seu contexto, incluindo aqueles que permeiam a relação entre gêneros."

\section{Considerações finais}

No Brasil, a Biologia é considerada por muitas estudiosas de gênero e ciência uma área relativamente igualitária no que se refere à participação de homens e mulheres. Entretanto, os dados levantados pela pesquisa apontam para a participação numericamente equilibrada apenas nos postos inferiores e intermediários, enquanto que nos postos mais elevados - direção de instituições de ciência e tecnologia, coordenação de importantes projetos de pesquisa e hierarquia acadêmica - as mulheres continuam sub-representadas.

Do ponto de vista do interesse específico da presente pesquisa, percebese que a participação da maioria das mulheres envolvidas no projeto ocupavase de atividades de pesquisa mais rotineiras, menos estimulantes e mais braçais, enquanto, um percentual mais significativo de homens esteve envolvido no processo de análise do material seqüenciado, das atividades de coordenação, elaboração e decisões do projeto.

A análise desses dados nos leva a questionar se as mudanças que estão ocorrendo nas Ciências Biológicas, geradas pela introdução e supervalorização das técnicas da Biologia Molecular, podem pesar negativamente sobre a participação feminina, pois, se durante o processo de pesquisa as mulheres se ocupam das atividades mais rotineiras e os homens das atividades mais analíticas, as chances delas construírem carreiras promissoras se reduzem.

Esse ciclo vicioso de "efeitos Matilda" resulta em avanços mais rápidos por parte dos homens na construção das carreiras científicas. Os biólogos coordenam mais pesquisas do tipo "jovens pesquisadores", não perdem oportunidades de fazer estágios no exterior, mesmo com o nascimento de filhos, e publicam mais do que as mulheres que tiveram filhos. Esses três fatores conjugados - recursos para pesquisa, estágio e publicação - aumentam as chances de obtenção de novos recursos para pesquisa, assim como aceleram as carreiras masculinas.

Diante desse quadro, é preciso repensar as ciências como processos produtivos e criar mecanismos eficientes para que as barreiras que se impõem sobre as trajetórias das mulheres nas ciências sejam no minimo minimizadas, esperando-se que o ambiente no qual se produz conhecimento, seja adequado às condições das mulheres. Como sugere Haraway, pode ser o encontro como o ciborgue, um ser híbrido, meio humano e meio máquina, polifônico, polivalente e estruturador de transformações históricas. 


\section{Referências}

FIORAVANTI, Carlos. As descobertas se multiplicam. Revista Pesquisa FAPESP, São Paulo, dezembro de 2000.

GEWIN, Virginia. Small steps toward campus child care. Nature, vol 437, 15 September 2005 , p. 446.

KYWIK, Svein e TEIGEN, Mari. Child care. research collaboration, and gender differences inscientific productivity. Science, Technology \& Human Value, v. 21. n. 1, Winter 1996 p. 54-71.

LEÓN, Orozco e LEÓN, Elena M. Sistema de recompensa na ciência: especificidades e condicionantes em algumas áreas do conhecimento. Tese de doutorado, Política Cientifica, Unicamp, 1998.

OSADA, Neide Mayumi. Fazendo gênero nas ciências: uma análise das relações de gênero nas ciências na produção do conhecimento do projeto genoma da FAPESP. Dissertação de mestrado, Unicamp, 2006.

ROSSITER, Margaret. The Matilda effect in science. Social Studies of Science, Vol. 23, no. 2 May 1993, p. 325-341.

VELHO, Léa e PROCHAZKA, Vivianna. No que o mundo da ciência difere dos outros mundos?, Com Ciência, Campinas, 2005. Disponível em:

<http://www.comciencia.br/reportagens/mulheres/13.shtml>.Acesso em out. 2005.

FAPESP - Fundação de Amparo à Pesquisa do Estado de São Paulo - é uma das principais agências públicas de fomento à pesquisa do Pais.

4 OSADA, Neide Mayumi. Fazendo gênero nas ciências: uma análise das relações de gênero nas ciências na produção do conhecimento do projeto genoma da FAPESP. Dissertação de mestrado, Unicamp, 2006.

5 CNPq, Conselho Nacional de Desenvolvimento Cientifico e Tecnológico, agência de fomento à pesquisa ligada ao Ministério de Ciência e Tecnologia.

6 CAPES, Comissão de Aperfeiçoamento de Pessoal de Nível Superior, agência de fomento à pesquisa ligada ao Ministério da Educação.

Empresa Brasileira de Pesquisa Agropecuária.

Projeto Genoma Xanthomona Citri, disponivel em: http://watson.FAPESP.br/xantho/main.htm

Biólogo, coordenador de laboratório geral na universidade 2, 59 anos

10 Engenheiro agrônomo, coordenador de laboratório de seqüenciamento da universidade 2, 41 anos

11 Engenheira agrônoma, coordenadora de laboratório de seqüenciamento na universidade 1, 45 anos

12 NATURE. All Thing Equal. Nature, v. 437, 15 set 2005, p. 296.

13 Comparativamente, a proporção de mulheres que obtém recursos do Auxilio Regular é de aproximadamente $52 \%$; esse Auxílio destina-se às pesquisas individuais para projetos de um ano, renovável por mais um ano e para projetos de orçamentos menores.

14 Biólogo, coordenador de laboratório geral na universidade 2, 59 anos.

15 Engenheira agrônoma, coordenadora de laboratório de seqüenciamento na universidade 1, 62 anos.

16 Engenheira agrônoma, coordenadora de laboratório de seqüenciamento na universidade 1, 62 anos.

17 Engenheira agrônoma, coordenadora de laboratório de seqüenciamento na universidade 1, 45 anos.

18 Bióloga, técnica de laboratório de seqüenciamento na universidade 2, 32 anos.

19 "A anotação genômica consiste num processo de vários passos, caindo, mais ou menos, em três categorias básicas: a anotação em nivel de nucleotídeos, anotação em nível de proteínas e anotação em nivel de processo. $\mathrm{Na}$ anotação em nivel de nucleotídeos, procura-se encontrar a localização Física das seqüências de DNA e descobrir onde estão os genes, RNAs, elementos repetitivos, etc. $\mathrm{Na}$ anotação em nivel protéico procura-se descobrir a provável função dos genes, 
identificando quais são aqueles que determinado organismo possui e quais ele não possui. Já a anotação em nivel de processo procura identificar as vias e processos nos quais diferentes genes interagem, montando uma anotação funcional eficiente." Fonte: PROSDOCIMI, Francisco. Anotação de Genomas. Bioinformática, Chico On-Line, Interpretando Genomas, UFMG, Minas Gerais, Disponivel em:

< http://www.icb.ufmg.br/ franc/cool/bioinfo/anotacao.htm>. Acesso em: Janeiro de 2006.

20 Engenheira agrônoma, coordenadora de laboratório de seqüenciamento na universidade 1, 62 anos.

21 Biólogo, coordenador de laboratório geral na universidade 2, 59 anos

22 Alellyx é uma empresa brasileira de biotecnologia especializada nos estudos da genômica aplicada à plantas. Elafoi criada por um grupo de pesquisadores do genoma da xylella, foi incentivada pela FAPESP e financiada pela Votorantim Novos Negócios .

23 Prêmio criado pela Revista Claudia que, desde 1997, premia mulheres de destaque nas ciências, na cultura, nos negócios, em trabalhos sociais e políticas públicas. A maioria das cientistas premiadas são da área da Biologia e trabalham com Genética e Biologia Molecular. A primeira cientista laureada foi Johanna Döbereiner, agrônọma que estudou a fixação de nitrogênio por bactérias em plantas leguminosas e gramíneas e uma das mulheres cientistas mais importantes do século XX.

24 Anamaria Camargo, Marilis do Valle Marques, Marie-Anne Van Sluys, Claudia Monteiro-Vitorello, Elizabeth Angélica Leme Martins, Ana Claudia Rasera da Silva e Mariana de Oliveira 